\title{
Erratum: Impact of managed aquifer recharge on the chemical and isotopic composition of a karst aquifer, Wala reservoir, Jordan
}

Julian Xanke • Nadine Goeppert • Ali Sawarieh •

Tanja Liesch • Jochen Klinger • Wasim Ali •

Heinz Hötzl • Khair Hadidi • Nico Goldscheider

Erratum to: Hydrogeology Journal (2015)

DOI 10.1007/s10040-015-1233-6

There is a spelling error in the author listing of the original article. Jochen Kinger should be Jochen Klinger.

Published online: 21 May 2015

(C) Springer-Verlag Berlin Heidelberg 2015

The online version of the original article can be found at http://dx.doi.org/ 10.1007/s10040-015-1233-6.

J. Xanke $(\bullet) \cdot$ N. Goeppert · T. Liesch · J. Klinger · W. Ali ·

H. Hötzl · N. Goldscheider

Division of Hydrogeology,

Karlsruhe Institute of Technology (KIT), Adenauerring 20b,

76131, Karlsruhe, Germany

e-mail: julian.xanke@kit.edu

Tel.: +49-721-608-41968

A. Sawarieh

Natural Resource Authority, P.O.Box 711118, Amman, Jordan

K. Hadidi

Water Authority Jordan, P.O. Box 241211183, Amman, Jordan 